\title{
Original Article \\ Hydroelectrophoresis for Transdermal Administration of Verapamil or of Hyaluronic Acid in Peyronie's Disease: A Prospective, Open-Label, Multicenter Study
}

\author{
Carlo Maretti ${ }^{1}$, Giorgio Cavallini ${ }^{2 *}$ \\ ${ }^{1}$ Department of Andrology, Centro Medico Cirm, Outpatient Clinic of Piacenza, Via Somaglia 10, \\ 29121 Piacenza, Italy, ${ }^{2}$ Department of Andrology, Gynepro-Medical Group, Via Tranquillo Cremona 8, \\ 40137 Bologna, Italy \\ Address for Correspondence: Giorgio Cavallini, Via Mascheraio 46, 44121 Ferrara, Italy. \\ Phone: +39-0532-200847, Fax: +39-0532-1860287. E-mail: giorgiocavallini@libero.it
}

Quick Access Code

How to cite this article: Maretti C, Cavallini G. Hydroelectrophoresis for Transdermal Administration of Verapamil or of Hyaluronic Acid in Peyronie's Disease: A Prospective, OpenLabel, Multicenter Study. Journal of Medical Research and Innovation. 2018;2(2):e000119.

Doi: 10.15419/jmri.119

Publication history: Received: 16-04-2018 Accepted: 04-06-2018 Published: 11-07-2018

Editor: Dr. Varshil Mehta

Copyright: Maretti C, Cavallini G. This is an open access article distributed under the terms of the Creative Commons Attribution License CC-BY 4.0., which permits unrestricted use, distribution, and reproduction in any medium, provided the original author and source are credited.

Funding: NIL

Conflict of Interest: NIL

\section{Abstract}

Aim and Objective: This study aims to assess the efficacy of a new electromotive system for the transcutaneous delivery of verapamil or of hyaluronic acid to improve the symptoms of Peyronie's disease (PD) in patients with a curvature deformity of $\angle 30^{\circ}$ at the beginning of therapy. Methods and Materials: A total of 61 PD patients were studied. 30 were randomly assigned to receive verapamil $10 \mathrm{mg} /$ session (Isoptin $^{\circledR}$, BGP Products, Rome-Italy) (Group 1, median age 56 years, range 49-62), and 31 were randomly assigned to receive hyaluronic acid $8 \mathrm{mg} / \mathrm{session}$ (Sinovial ${ }^{\circledR}, \mathrm{IBSA}$, Lodi-Italy) (Group 2, median age 58 years, range 51-56). There were 10 sessions, 2 sessions/week for each drug. Each drug was transdermally administered using the hydroelectrophoresis technique and carried out using a Hydro4 and apparatus (Swiss4Med SA, Morbio Inferiore, Switzerland). With respect to the efficacy of the drugs studied, the end points were side effects, pain, erectile function, penile deviations and plaque area $\left(\mathrm{cm}^{2}\right)$ before, and 3 and 6 months after drug administration. The differences were assessed using the Mann-Whitney rank test (unmatched groups) or using the Wilcoxon signed-rank test (matched groups). The differences between the groups in terms of side effects were assessed using the Chi-square test. Results: No significant difference emerged among the baseline values of the two groups. Pain, erectile function, plaque area, and penile deformity significantly improved in both groups after treatment, but a notably higher improvement occurred in the patients in whom hyaluronic acid was administered. Only a few negligible side effects occurred in the Group 1 patients treated with verapamil, with no significant difference between the groups. Conclusion: Administration of both hyaluronic acid and verapamil using the Hydro4 and apparatus is a safe and efficient method for PD therapy.

Keywords: Hyaluronic acid, hydroelectrophoresis, medical therapy, Peyronie's disease, verapamil

\section{Introduction}

Peyronie's disease (PD) is a disorder of the penis characterized by plaques of fibroblast proliferation/fibrosis located in the tunica albuginea. The plaques may cause a variety of deformities. Pain and erectile dysfunction may be accompanying symptoms. ${ }^{[1]}$ Originally, PD was regarded as a phenomenon which spontaneously resolved itself; however, more recent studies have indicated that few or no patients experienced disease resolution, whereas in a large majority of patients, the disease worsened. ${ }^{[1,2]}$ PD might be considered a tumor-like disease; ${ }^{[3]}$ thus, effective conservative therapy might be particularly welcome in the early stages of the disease.

Intralesional injection therapy with collagenase clostridium histolyticum ( $\mathrm{CCH}$ ) has been approved 
by the U.S. Food and Drug Administration for the treatment of adult men with PD having palpable plaques. The severity of the side effects (penile hematoma and/or corporeal rupture) and high costs has limited the use of $\mathrm{CCH}$ for a curvature deformity of $\geq 30^{\circ}$ at the beginning of therapy. ${ }^{[4]}$

This means that a number of PD patients still require non$\mathrm{CCH}$ medical therapy capable of eliminating or improving PD symptoms.

Intraplaque injection of hyaluronic acid recently showed a higher efficacy than intraplaque verapamil in improving plaque size and sexual function in PD patients. ${ }^{[5]}$ Intraplaque injections are painful, may provoke hematomas, and a consistent number of patients have refused the treatment. ${ }^{[6]}$

These data prompted us to test a new electromotive system for the transcutaneous delivery of verapamil or of hyaluronic acid in a prospective open trial with the purpose of improving PD symptoms in patients with curvature deformity of $<30^{\circ}$ at the beginning of therapy.

\section{Materials and Methods}

\section{Patients}

This was a prospective multicenter study. All patients complaining of untreated/undiagnosed PD were considered for inclusion in the study. These patients were enrolled between January 2, 2014, and September 30, 2017. PD is defined by the presence of plaques in the tunica albuginea of the penis; the PD was diagnosed based on medical history, physical examination, and basal and dynamic duplex scanning of the penis (i.e., after intracavernosal injection of Alprostadil prostaglandin E1 [PGE1] $20 \mu \mathrm{g}) .{ }^{[6]}$

The following laboratory assessments were carried out on each patient: Body mass index (body mass index = weight in $\mathrm{kg} /$ height $^{2}$ in $\mathrm{m}^{2}$ ), blood pressure measurement, blood count, SGOT, SGPT, blood sugar, glycated hemoglobin, and prostate-specific antigen. The following assessments were carried out before and after drug intervention.

Objective information pertaining to the nature and magnitude of the patient's penile deviation was obtained using an intracavernous injection (ICI) with $20 \mu \mathrm{g}$ of Alprostadil (PGE1). A second injection was planned to be administered if necessary to achieve full erectile response, but this was never necessary since all patients were able to achieve full rigidity with the first $\mathrm{ICl}$. The penile deviations were assessed on the basis of photo archives gathered in the outpatient clinic using the Kelami method $^{[7]}$ and calculated using a paper protractor. ${ }^{[8]}$

The following parameters were assessed before intervention: Pain on erection using a visual pain scale of $1-10,,^{[9]}$ satisfaction with vaginal penetration according to the international index of erectile dysfunction (IIEF)15 scale score, ${ }^{[10]}$ penile deviation (in degrees), ${ }^{[7]}$ and plaque size $\left(\mathrm{cm}^{2}\right)$ as assessed using ultrasonography + ICI PGE1, $20 \mu \mathrm{g}$. In the case that more than one plaque was present, the total size and volume of all plaques were recorded in each patient. ${ }^{[2]}$ The same parameters were again assessed 3 and 6 months after the end of the interventions. ${ }^{[6]}$ The acute and chronic side effects of the treatments were assessed as well.

\section{Inclusion criteria}

All patients in whom PD could be diagnosed were considered candidates for the present study. A power analysis was carried out to estimate the number of observations required to have a reliable chance of detecting the effect sought. There are no formal standards for power $(\pi)$; the power of our tests used $\pi=0.90$ as a standard for adequacy. ${ }^{[11]}$ The calculations were carried out using the $\mathrm{G}^{*}$ Power3 program. ${ }^{[12]}$

\section{Exclusion criteria}

The exclusion criteria were the following: Refusal to participate in the study (12 cases), previous penile surgery or trauma ( 2 cases), pelvic surgery (6 cases), uncompensated diabetes/ hypertension (13 cases), tobacco and/or alcohol abuse (12 cases), penile deviation $>30^{\circ}$ (34 cases), and any previous treatment for PD (21 cases). ${ }^{[6]}$

\section{Patient randomization}

Randomization was carried out using an online randomizer: https://www.randomizer.org/. The patients were randomized into two groups, the first receiving verapamil 10/mg session, 2 sessions/week for 10 weeks and the second receiving hyaluronic acid $8 \mathrm{mg} / \mathrm{session}, 2$ sessions/week for 10 weeks. Blindness could not be insured because the mixture gel + drug is best used immediately after preparation, and the mixture was prepared by the researchers since no nurse was available. The majority of the papers in which verapamil was used for PD used $10 \mathrm{mg}$ of the drug. ${ }^{[5,13,14]}$

The dosage of the hyaluronic acid was assessed on the basis of previous preparation tests, carried out by collecting data on a visual pain scale score, an IIEF15 scale score, ${ }^{[10]}$ penile deviation (in degrees), ${ }^{7}$ and plaque size $\left(\mathrm{cm}^{2}\right)$ as assessed using ultrasonography + ICI PGE1, $20 \mu \mathrm{g}$ before and after hyaluronic acid administration. One vial/session was administered to one group of 10 PD patients and two vials/sessions were administered to another group of 10 PD patients. 2 sessions/week for 5 weeks were carried out for each patient. Since the visual pain scale score, the IIEF15 scale score, penile deviation, and plaque size were equally improved in all patients in both groups, a dosage of one hyaluronic acid vial/session was adopted.

\section{Hydroelectrophoresis technique}

Hydroelectrophoresis was performed using a Hydro4 and apparatus (Swiss4Med SA, Morbio Inferiore, Switzerland) 
[Figure 1]. Briefly, hyaluronic acid $8 \mathrm{mg}$ (1 ml vial) (Sinovial ${ }^{\circledR}$ Mini 0,8\%; IBSA, Lodi, Italy) or verapamil 10 mg (Isoptin ', BGP Products, Rome-Italy) were combined and mixed in one bottle containing $10 \mathrm{ml}$ specific gel (hydro4gel ${ }^{\mathrm{TM}}$ ). The mixture Hydro4 gel and drug were placed within a special polarization chamber (ROLL-ON). The apparatus was set at the appropriate level "severe PD," and the polarized chamber was rolled up and down on the flaccid penis in correspondence of the plaque until the polarization chamber was empty. ${ }^{[15]}$ The procedure was repeated twice a week for 5 weeks.

\section{End points and statistical analysis}

With respect to the efficacy of the drugs studied, the end points were side effects, pain grade, IIEF15 score, penile deviations,

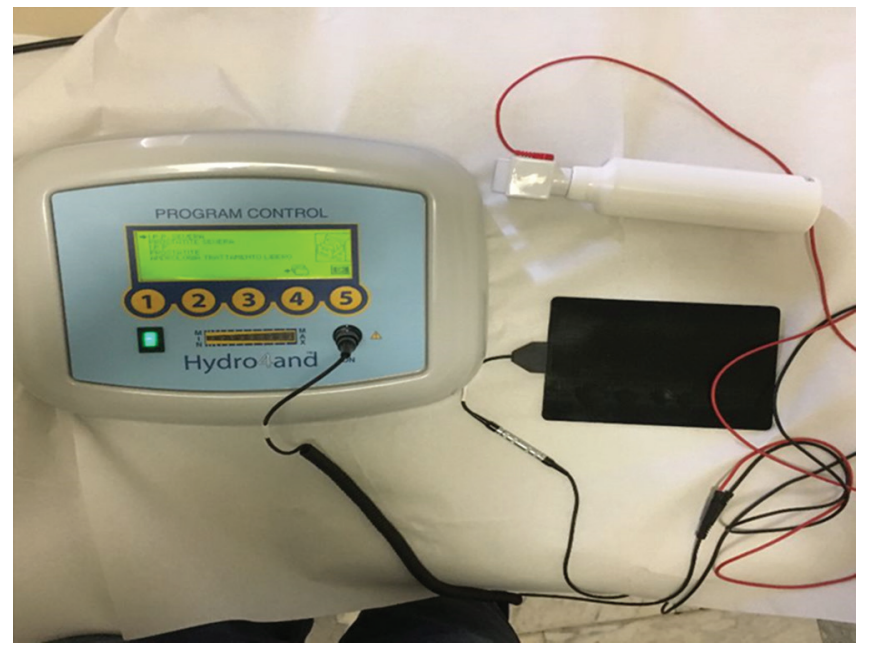

Figure 1: Complete figure of the Hydro4 and apparatus (Swiss4Med SA, Morbio Inferiore, Switzerland). *The apparatus was set at the appropriate level "Severe Peyronie's Disease." A white bottle contained hyaluronic acid $8 \mathrm{mg}$ (Sinovial ${ }^{\circledR}$ Mini $0,8 \%$; IBSA, Lodi, Italy) or verapamil $10 \mathrm{mg}$ (Isoptin ${ }^{\circledR}$, BGP Products, Rome-Italy) $+10 \mathrm{ml}$ specific gel (hydro4gel ${ }^{\mathrm{TM}}$ ). The white bottle is attached to the special polarization chamber (ROLL-ON). The polarized chamber was rolled up and down on the flaccid penis in correspondence of the plaque until the polarization chamber and the bottle were empty and plaque area $\left(\mathrm{cm}^{2}\right)$ as assessed using ultrasonography $+\mathrm{ICl}$ PGE1, $20 \mu \mathrm{g}$.

The differences between the unmatched groups were assessed using the Mann-Whitney rank test, and the differences between before and after (matched groups) therapy were assessed using the Wilcoxon signed-rank test. The side effects were compared between the two groups using the chi $^{2}$ test. ${ }^{[11]}$

\section{Results}

A total of 66 patients were eligible for participation in the study; 32 were randomly assigned to receive verapamil (Group 1) and 34 hyaluronic acid (Group 2). Two patients in Group 1 violated the protocol, and three dropped out from Group 2. A phone call indicated that, in 2 cases, a transfer of residence had occurred and, in the last case, there was a couple conflict. Thus, 30 patients treated with verapamil $10 \mathrm{mg}$ and 31 treated with hyaluronic acid $8 \mathrm{mg}$ were studied.

Table 1 summarizes the baseline demographic and clinical characteristics for each group. No significant differences emerged.

Table 2 summarizes the results of each study group, i.e. side effects, pain grade, IIEF15 score, penile deviations, and plaque area before and after the administration of verapamil or of hyaluronic acid. No significant differences emerged among the baseline values of the two groups. Pain score, IIEF 15 score, plaque area, and penile deformity notably improved in both groups 3 and 6 months after treatment, but a significantly higher improvement occurred in the Group 2 patients, i.e., in the patients in whom hyaluronic acid was administered. No significant difference existed between the data of Group 1 at 3 and 6 months; likewise, no significant difference occurred between the data of Group 2 at 3 and 6 months. Only a few negligible acute side effects occurred in the Group 1 patients treated with verapamil, with no significant difference between the groups. No chronic side effects occurred in either group.

Table 1: Baseline demographic and clinical characteristics for each group participating in the study

\begin{tabular}{|c|c|c|c|}
\hline & $\begin{array}{c}\text { Group 1: } 30 \text { patients treated with } \\
10 \text { hydroelectrophoretic rounds, } \\
\text { each round carried out with } \\
\text { verapamil } 10 \mathrm{mg}\end{array}$ & $\begin{array}{l}\text { Group 2: } 31 \text { patients treated with } \\
10 \text { hydroelectrophoretic rounds, } \\
\text { each round carried out with } \\
\text { hyaluronic acid } 8 \mathrm{mg}\end{array}$ & P value \\
\hline Age in years & $56(49-62)$ & $58(51-56)$ & 0.345 \\
\hline Mean $\mathrm{BMI}$ in $\mathrm{Kg} / \mathrm{m}^{2}$ & $24(20-28)$ & $23.5(20-27)$ & 0.310 \\
\hline $\begin{array}{l}\text { Compensated } \\
\text { hypertension (\%) }\end{array}$ & $12(40)$ & $11(35.5)$ & 0.207 \\
\hline Dupuytren's contracture (\%) & 0 & 0 & Not tested \\
\hline Compensated diabetes (\%) & $6(20)$ & $7(22.6)$ & 0.434 \\
\hline
\end{tabular}

*Data are shown as median values, and the ranges are in parentheses; the difference between the median values was examined using the Mann-Whitney rank test. Differences between percentual data were examined using the Chi-square test. No significant difference ever emerged. BMI: Body mass index 


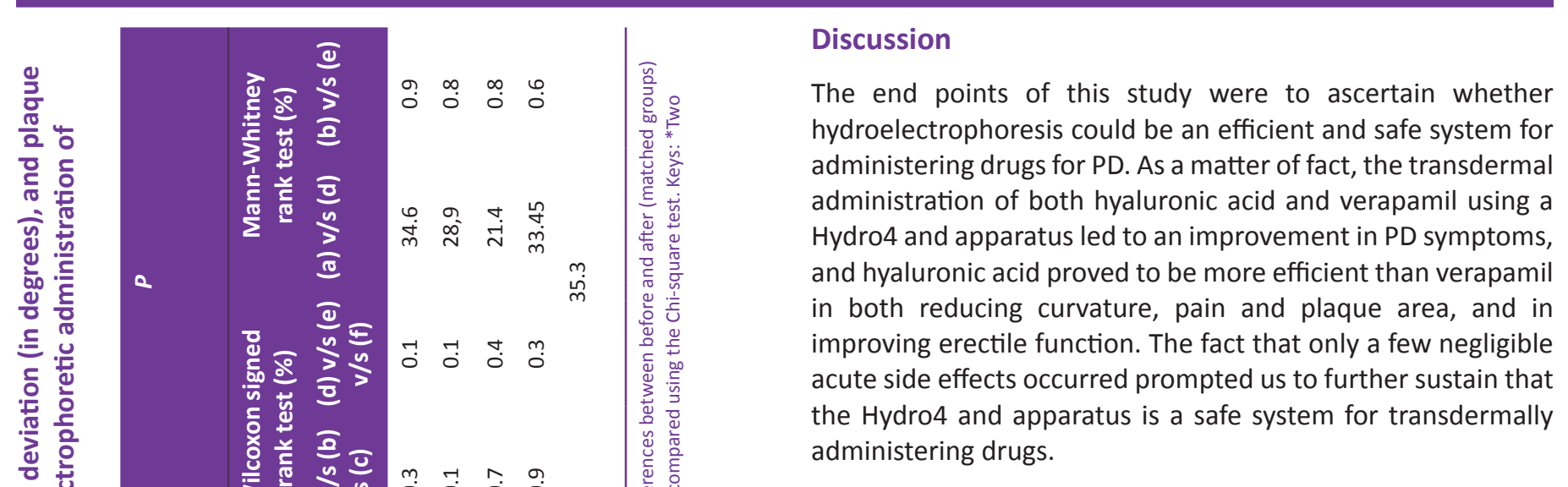

Verapamil and hyaluronic acid display a number of characteristics which might be useful in resolving PD symptoms. Hyaluronic acid decreases the production of the pro-inflammatory cytokine tumor necrosis factor- $\alpha$, prevents apoptosis, increases cell survival, prevents fibrosis, reduces inflammation and heterophile infiltration, improves neoangiogenesis, and reduces pain and burning sensation. ${ }^{[16]}$

Verapamil alters the fibroblast production of extracellular matrix macromolecules, inhibiting exocytosis of the extracellular matrix; it inhibits the expression of collagen and increases the proteolytic activity of collagenase, thereby enhancing matrix remodeling by human fibroblasts. It also affects the cytokine expression associated with the early phases of wound healing and inflammation and possesses a profound inhibitory effect on cell proliferation. ${ }^{[17]}$

\section{Limitations}

\section{This paper has three biases}

The first was that no placebo was used. As a matter of fact, it was quite impossible to find a placebo substance for PD because even the intralesional administration of a physiologic solution significantly reduces plaque size. ${ }^{[17-19]}$

The second was that the authors were unblinded to the drug used. However, pain and sexual function assessment was carried out by administering a validated questionnaire to the patients; thus, the results of the therapies were evaluated by the patients themselves. Additional plaque area and penile deformity assessments were carried out using objective methods (photography, dynamic duplex, and paper protractor) to reduce the influence of the authors as much as possible.

The third was that no branch made up of untreated patients was tested. Currently, the Helsinki declaration of human rights (http://www.partecipasalute.it/cms/files/Dichiarazione\%20 di\%20Helsinki.pdf) precludes the possibility of not treating patients when they are recognized to be affected by a progressive disease, and PD is a progressive disease in the majority of the cases. ${ }^{[1,2]}$ 


\section{Conclusion}

As a conclusion, hydroelectrophoresis performed with a Hydro4 and apparatus is a safe and efficient method for delivering transcutaneous drugs to relieve PD symptoms.

\section{References}

1. Levine LA. The clinical and psychosocial impact of Peyronie's disease. Am J Manag Care 2013;19 4 Suppl: S55-61.

2. Paulis G, Cavallini G. Clinical evaluation of natural history of Peyronie's disease: our experience, old myths and new certainties. Inflamm Allergy Drug Targets 2013;12:341-8.

3. Zorba OU, Sirma S, Ozgon G, Salabas E, Ozbek U, Kadioglu A. Comparison of apoptotic gene expression profiles between Peyronie's disease plaque and tunica albuginea. Adv Clin Exp Med 2012;21:607-14.

4. Lipshultz LI, Goldstein I, Seftel AD, Kaufman GJ, Smith TM, Tursi JP, et al. Clinical efficacy of collagenase Clostridium histolyticum in the treatment of Peyronie's disease by subgroup: results from two large, double-blind, randomized, placebo-controlled, phase III studies. BJU Int 2015;116:650-6.

5. Favilla V, Russo GI, Zucchi A, Siracusa G, Privitera S, Cimino $S$, et al. Evaluation of intralesional injection of hyaluronic acid compared with verapamil in Peyronie's disease: preliminary results from a prospective, doubleblinded, randomized study. Andrology 2017;5:771-5.

6. Cavallini G, Modenini F, Vitali G. Open preliminary randomized prospective clinical trial of efficacy and safety of three different verapamil dilutions for intraplaque therapy of Peyronie's disease. Urology 2007;69:950-4.

7. Kelâmi A. Autophotography in evaluation of functional penile disorders. Urology 1983;21:628-9.
8. Maretti C. Symptoms, their physiopathology and outpatient clinic practice and diagnosis. In: Cavallini G, Paulis G, editors. Peyronie's Disease: A Comprehensive Guide. $1^{\text {st }} \mathrm{ed}$. Heidelberg: Springer Berliner Verlag; 2015. p. 47-57.

9. Price DD, McGrath PA, Rafii A, Buckingham B. The validation of visual analogue scales as ratio scale measures for chronic and experimental pain. Pain 1983;17:45-56.

10. Rosen RC, Riley A, Wagner G, Osterloh IH, Kirkpatrick J, Mishra A. The international index of erectile function (IIEF): a multidimensional scale for assessment of erectile dysfunction. Urology 1997;49:822-30.

11. Armitage P. Statistical Methods in Medical Research. $2^{\text {nd }}$ ed. Oxford: Blackwell Scientific Publishers; 1971.

12. Faul F, Erdfelder E, Buchner A, Lang AG. Statistical power analyses using G*Power 3.1: tests for correlation and regression analyses. Behav Res Methods 2009;41:1149-60.

13. Swiss4med. Hydro4and Operating Manual; 2013. Available from: http://www.swiss4med.ch/2-swiss4med.html

14. Aliperti LA, Mehta A. Peyronie's disease: Intralesional therapy and surgical intervention. Curr Urol Rep 2016;17:60.

15. Pires J, Travis M, Ellsworth P. Peyronie's disease: Overview and recent treatment advances. Urol Nurs 2015;35:164-78.

16. Neuman MG, Nanau RM, Oruña-Sanchez L, Coto G. Hyaluronic acid and wound healing. J Pharm Pharm Sci 2015;18:53-60.

17. Levine LA, Estrada CR. Intralesional verapamil for the treatment of Peyronie's disease: a review. Int J Impot Res 2002;14:324-8.

18. Dang G, Matern R, Bivalacqua TJ, Sikka S, Hellstrom WJ. Intralesional interferon-alpha-2B injections for the treatment of Peyronie's disease. South Med J 2004;97:42-6.

19. Rehman J, Benet A, Melman A. Use of intralesional verapamil to dissolve Peyronie's disease plaque: a longterm single-blind study. Urology 1998;51:620-6. 